\title{
Right Sided Haemorrhagic Pleural Effusion Secondary to Pancreatitis- A Case Report
}

\author{
Rohit R. Chandran ${ }^{1}$, K. N. Mohan Rao², Tina Sakariah ${ }^{3}$, Shukla A. K. ${ }^{4}$, Kanabur Prasanth ${ }^{5}$
}

\begin{abstract}
${ }^{1}$ Department of Pulmonology, Rajarajeswari Medical College and Hospital, Bangalore, Karnataka, India. 2Department of Pulmonology, Rajarajeswari Medical College and Hospital, Bangalore, Karnataka, India. ${ }^{3}$ Department of Pulmonology, Rajarajeswari Medical College and Hospital, Bangalore, Karnataka, India. ${ }^{4}$ Department of Radiology, Rajarajeswari Medical College and Hospital, Bangalore, Karnataka, India. ${ }^{5}$ Department of Pulmonology, Rajarajeswari Medical College and Hospital, Bangalore, Karnataka, India.
\end{abstract}

\section{PRESENTATION OF CASE}

A 28-year-old male patient, painter by occupation came to the department of pulmonology of Rajarajeswari Medical College, Kambipura, Karnataka, with complaints of right sided chest pain since 4 months, dry cough since one month and loss of appetite with significant weight loss. The patient was a chronic alcoholic and a non-smoker. History revealed that he was admitted in a primary health care centre for one week with similar complaints 3 months back and chest radiographs were taken. The radiograph showed right sided massive pleural effusion for which diagnostic thoracocentesis was done, which revealed haemorrhagic fluid. Pleural fluid analysis showed lymphocytic predominance; there after, repeated thoracocentesis was done in the same primary health centre and up to 5 litres of haemorrhagic pleural fluid was aspirated. Routine blood reports were within normal limits.

This patients was then referred to our hospital as there was no improvement in his symptoms. Chest radiograph and ultrasound (USG) on admission showed right side massive effusion (approximate volume of $1400 \mathrm{cc}$ ) with mediastinal shift. Diagnostic thoracocentesis showed frank pus, which was neutrophil predominant, exudative and revealed grossly elevated levels of amylase, lipase and lactate dehydrogenase (LDH) (>1200 U/L) (table 1). Intercostal drainage tube (ICD) was put in view of empyema and $4 \mathrm{~L}$ of frank pus was drained which turned haemorrhagic in due course. Blood investigations showed mild anaemia and elevated serum amylase and lipase. Meanwhile the patient was treated with Injection Ceftriaxone 1gm BD which was changed to Injection Tazobactam 4.5 gm TID with Injection Clindamycin $600 \mathrm{mg}$ TID. Sputum was negative for Acid fast bacilli (AFB) and culture showed no growth.

Since repeat chest radiographs showed no resolution, contrast enhanced computed tomography (CECT) thorax and abdomen was done which showed large right sided pyopneumothorax with mediastinal shift/lymphadenopathy and a loculated/walled of necrotic collection/pseudocyst in the region of head/uncinate process of pancreas (fig 1). As haemorrhagic pleural fluid was re accumulating, Magnetic Resonance cholangio pancreatography was done to demonstrate any connection, which showed no obvious connection fig. 3. Patient was treated conservatively for 3 weeks for pancreatitis and followed up with serial ultrasound scans and there was decrease in the pleural collection (fig. 2). The patient was then referred to cardiothoracic vascular surgeon (CTVS) and open thoracotomy and decortication was done following which patient improved and discharged on $25^{\text {th }}$ July 2019 and is on regular follow up.
Corresponding Author: Dr. Rohit R. Chandran, Chandra Villa, PO. West Hill Chungam, Kozhikode-673005, Kerala, India. E-mail: drrohitchandran@gmail.com

DOI: $10.14260 /$ jemds/2020/264

Financial or Other Competing Interests: None.

How to Cite This Article:

Chandran RR, Rao KNM, Sakariah T, et al. Right sided haemorrhagic pleural effusion secondary to pancreatitis- a case report. J. Evolution Med. Dent. Sci. 2020;9(14):12201222, DOI: 10.14260/jemds/2020/264

Submission 29-01-2019,

Peer Review 13-03-2020,

Acceptance 20-03-2020,

Published 06-04-2020.

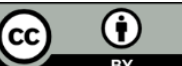




\section{CLINICAL DIAGNOSIS}

Right Sided Haemorrhagic Pleural Effusion.

\section{DIFFERENTIAL DIAGNOSIS}

1. Tuberculous Pleural Effusion.

2. Pleural Effusion Secondary to Pancreatitis.

\section{PATHOLOGICAL DISCUSSION}

Haemorrhagic Pleural effusion often occurs as a complication of pancreatic disorders like acute and chronic pancreatitis, pseudocyst, pancreatic abscess. In $15-20 \%$ cases, the cause remains undiagnosed despite all efforts ${ }^{1}$. Previously, the incidence of pleural effusion in acute pancreatitis was 3-7\%. However, present studies show pleural effusion in up to $50 \%$ cases, detected by computed tomography (CT) scan, owing its higher sensitivity. ${ }^{2,3}$ Pleural effusion as a consequence of acute pancreatitis is transient, usually left sided, straw coloured and accounts for $1 \%$ of all the cases of pleural effusion. Rarely it might be right sided and haemorrhagic, causing difficulty in establishing the diagnosis, especially when chest symptoms are disproportionately more than abdominal symptoms. Pleural effusion with a very high pancreatic enzymes activity most frequently occurs in patients with alcoholic pancreatitis. ${ }^{4}$

Pleural effusions due to pancreatic diseases are mostly reactive with slightly elevated amylase levels. Very high levels of amylase in the pleural fluid are rare and can only be explained by the rupture of a pancreatic pseudocyst with perforation into the pleural cavity such as by drainage of pancreatic fluid into the pleural cavity. ${ }^{1}$ Regarding elevated pleural fluid amylase, perforation of pseudocyst into the pleural cavity seems to be the mechanism of haemorrhagic pleural effusion in our case. Pancreatic pseudocyst have been found in $69-77 \%$ of patients with pancreaticopleural fistula(PPF). ${ }^{5}$ Pancreaticopleural fistula (PPF) is an unusual complication of acute or chronic pancreatitis or pancreatic trauma $(<1 \%){ }^{6} 30 \%$ of pancreatic pleural effusion can occur without any PPF. ${ }^{2}$ Visual methods such as computed tomography was able to diagnose fistula only in $33-47 \%$ (sensitivity) of cases, Magnetic Resonance Cholangiopancreaticography (MRCP) a noninvasive test has (80\%) sensitivity to demonstrate PPF, Endoscopic Retrograde Cholangiopancreaticography (ERCP) an invasive test has sensitivity of (46-78\%) in demonstrating PPF.7

\begin{tabular}{|ccccc|}
\hline Date & $\begin{array}{c}\text { Serum } \\
\text { Amylase } \\
\text { U/L }\end{array}$ & $\begin{array}{c}\text { Pleural } \\
\text { Amylase } \\
\text { U/L }\end{array}$ & $\begin{array}{c}\text { Serum } \\
\text { Lipase } \\
\text { U/L }\end{array}$ & $\begin{array}{c}\text { Pleural } \\
\text { Lipase } \\
\text { U/L }\end{array}$ \\
$19 / 3 / 2019$ & 40 & & 597 & \\
$09 / 04 / 2019$ & 163 & & 85 & \\
$13 / 06 / 2019$ & & 927 & 57 & \\
$15 / 06 / 2019$ & 112 & 926 & 92 & 226 \\
$20 / 06 / 2019$ & 174 & & 102 & \\
$25 / 06 / 2019$ & 240 & & \\
\hline \multicolumn{4}{c}{ Table 1. Values of Serum and Pleural } \\
& Pancreatic Enzymes Over the Days \\
\hline
\end{tabular}
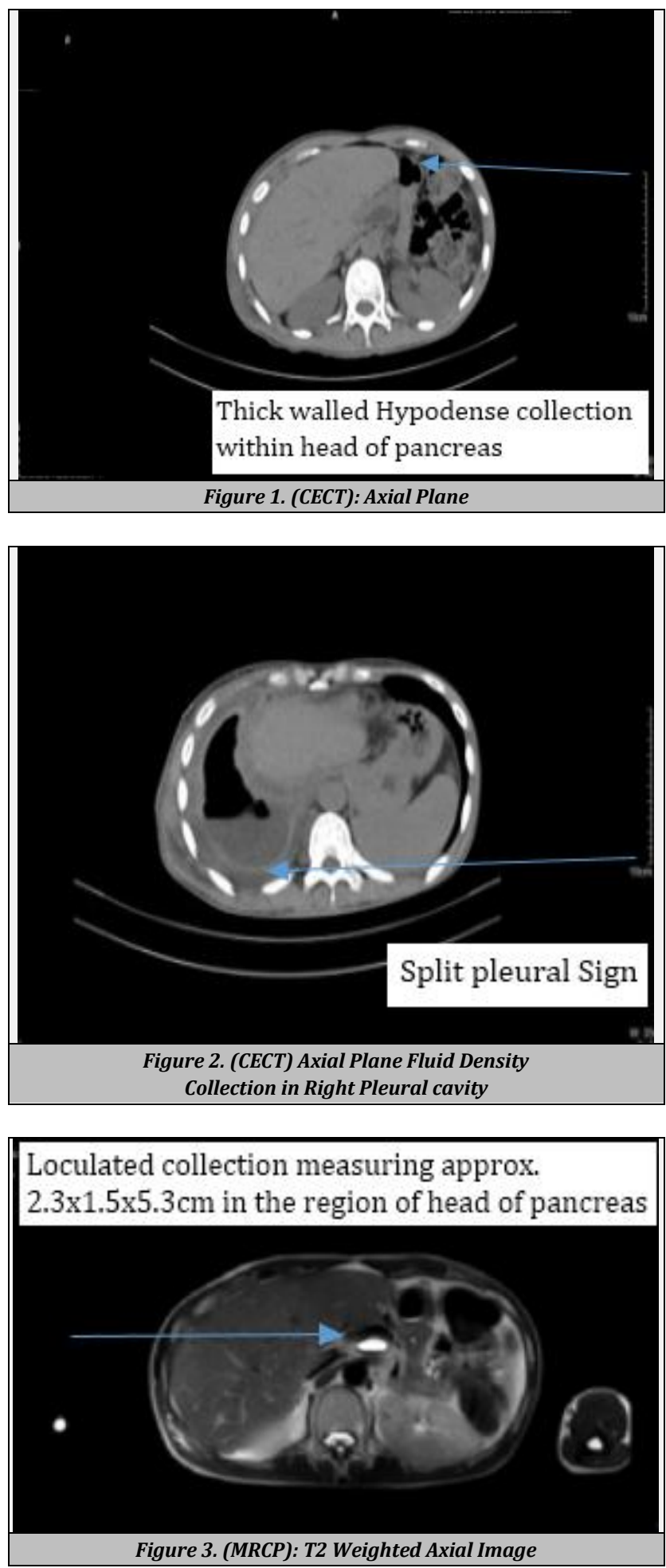

\section{DISCUSSION OF MANAGEMENT}

Available treatment modalities includes, drainage by a chest tube with concomitant conservative/medical management for pancreatitis and is usually effective in massive pancreatic pleural effusions. If drainage by a chest tube fails, percutaneous catheter drainage of the abdominal pseudocyst can be considered 6 . The aim of medical management is to reduce stimulation of pancreatic exocrine secretions. Medical treatment consists of thoracocentesis and/or tube thoracostomy and administration of somatostatin analogues and pancreatic enzyme supplements which can be continued 
for 2-4 weeks. Octreotide can be given for 2-5 months ${ }^{8}$. Conservative treatment has a success rate of $30-60 \%$ with a recurrence rate of $15 \%$ and mortality of $12 \%$.

Other modality of treatment includes ERCP with or without endoscopic pancreatic stent placement and surgery which is very effective for fistulas present in head and uncinated process of pancreas. Use of stents is to drain fistulas as short term treatment and drainage of stenosed pancreatic duct as long term management. ${ }^{9}$ Other surgical option includes pancreatic resection and closure of the ductal disruption or enteropancreatic anastomosis to site of pancreatic duct leakage or to the pseudocyst if medical treatment fails. Operative treatment has a success rate of $90 \%$ and recurrence rate of $18 \%$.Since no fistula was demonstrated in our case stent placement was not consider.

\section{FINAL DIAGNOSIS}

Right sided Haemorrhagic Pleural Effusion Secondary to Pancreatitis.

\section{REFERENCES}

[1] Rockey DC, Cello JP. Pancreaticopleural fistula. Report of 7 patients and review of the literature. Medicine (Baltimore) 1990;69 (6):332-44.
[2] Lankisch PG, Dröge M, Becher R. Pleural effusions: a new negative prognostic parameter for acute pancreatitis. Am J Gastroenterol 1994;89 (10):1849-51.

[3] Bedi RS. Massive pleural effusion due to asymptomatic pancreatic disease. Lung India 2006;23 (4):163-4.

[4] Girbes AR, Postmus PE, Jansen W, et al. An alcoholic with pleural effusion. Eur Respir J 1990;3 (8):934-6.

[5] Wakefield S, Tutty B, Britton J. Pancreaticopleural fistula: a rare complication of chronic pancreatitis. Postgrad Med J 1996;72 (844):115-6.

[6] Moorthy N, Raveesha A, Prabhakar K. Pancreaticopleural fistula and mediastinal pseudocyst: An unusual presentation of acute pancreatitis. Ann Thorac Med 2007;2 (3):122-3.

[7] Uchiyama T, Suzuki T, Adachi A, et al. Pancreatic pleural effusion: case report and review of 113 cases in Japan. Am J Gastroenterol 1992;87 (3):387-91.

[8] Safadi BY, Marks JM. Pancreatic-pleural fistula: the role of ERCP in diagnosis and treatment. Gastrointest Endosc 2000;51 (2):213-5.

[9] Gumaste V, Singh V, Dave P. Significance of pleural effusion in patients with acute pancreatitis. Am J Gastroenterol 1992;87 (7):871-4. 